\title{
A New History of Temporal Typography: Towards Fluid Letterforms
}

Journal of Design History (2014) 27 (2): 167-181.

Dr Barbara Brownie

Word count: 7897

\section{Summary}

Fluid typographic forms (letters, numbers, and other characters), which transform over time to present new identities, are employed in a new kind of temporal typography. These forms, and the behaviours they exhibit, are most commonly seen in temporal media, including television idents, credit sequences, and typographic animation. However, fluidity is dependent on characteristics that were developed historically, from the seventeenth to twentieth centuries. It has become possible to retrospectively identify the ways that historical developments anticipated fluid transformation in temporal typography. Some categories of fluid behaviour would be impossible if it were not for the concept of the letter as malleable, as a three-dimensional object, or as modular. These characteristics permit processes, or fluid behaviours, through which a new identity is introduced to a changing form. This article demonstrates that these three characteristics are reflected in three historical developments: the use of the transformable grid in the development of Romain du Roi, three-dimensional nineteenth-century typefaces, and the modular lettering of Josef Albers, Theo van Doesburg and Bart van der Leck.

\section{Keywords}

Typography, graphic design, graphic design history, modernist typography, branding 


\section{Fluid behaviours in temporal typography}

The field of practice identified by Y.Y.Wong as 'temporal typography’1 increasingly involves more complex motion or change. Previously, the typography in temporal media (appearing in credit sequences, typographic animation, and television idents) has been largely defined as 'motion typography', to the extent that the terms 'temporal typography' and 'motion typography' are often, incorrectly, treated as synonymous. However, as temporal typography becomes more widespread, on-screen typographic forms operate behaviours that are more complex than simple motion. Though many examples of temporal typography simply scroll across the screen or are subjected to cinematic transitions rather than motion, some more complex artefacts present letterforms that transform on the screen. In his holographic poetry, Eduardo Kac identified 'fluid' typographic forms that evolve over time, transforming to the extent that they abandon their verbal identity and acquire new identities. ${ }^{2}$ Equivalent transformation can be seen in temporal media, in examples such as recent Channel 4 idents.

Fluidity has been neglected in many previous studies of temporal typography. Texts by Woolman and Bellantoni, and Johnny C. Lee et al., describe 'motion' or kineticism, but rarely differentiate between different kinds of kineticism. ${ }^{3}$ In particular, motion and 'other temporal change' are rarely distinguished from one another, and where they are acknowledged, these 'other kinds of change' are not fully explored. Most make the same mistake as Gordon L. Shaw, assuming that 'the identity of an object moving on the screen is constantly preserved' ${ }^{4}$ In this assumption, motion and change considered only in so far as they affect the overall composition and design of a typographic arrangement, not the identity of an individual letter. Fluid transformations are more complex than simple motion, as they alter the appearance, shape and nature of individual letters. In fluid typography, letterforms transform to become other letters, pictures or objects, hence altering their fundamental identity. As a result of this transformation, fluid forms cannot be consistently 
described as, in Kac's terms, 'verbal'. ${ }^{5}$ They are, at different points in their transformation, verbal, pictorial, or 'asemic' (appearing to be writing or typography, but having no specific verbal identity). ${ }^{6}$

Fluid forms lose and acquire their various identities through several different behaviours: metamorphosis, revelation, or construction (as identified by the author in previous texts). ${ }^{7} \mathrm{I}$ propose that the origins of these behaviours, and so the origins of fluidity, can be identified in three distinct developments that have occurred in the history of static typography. In metamorphosis, a form has malleable contours, and through severe warping of those contours, changes shape until it is no longer recognisable as one letter, and instead becomes recognisable as another letter, image or object. This behaviour is reliant on the notion of a letter as a form that has several states, and may be transformed between those states. This notion was introduced through the creation of the 'penche' (italic) version of Romain du Roi, when the use of a grid allowed the manipulation of a typeface to produce alternative states of the same form. In revelation, a letter is revealed to have multiple identities as its different surfaces are revealed over time, either through rotation of the object or through navigation around it. This is only possible if the letter is perceived as having multiple different surfaces, each with different features. This is the case with three-dimensional typographic objects, such as those that began to appear frequently in eighteenth century woodblock typefaces. In construction, a form breaks apart and those parts re-form into a different arrangement. In this new arrangement, the collection of parts is perceived as having a different identity as in its initial appearance on the screen. This behaviour may only occur as a consequence of the notion of a letter as modular, constructed from separate parts, as in the modernist lettering of Josef Albers, Theo van Doesburg and Bart van der Leck. These designers presented letters that were constructed from separate interchangeable shapes or 'primitives' ${ }^{8}$ 
Since the introduction of screen-based temporal media, commentators and historians have retrospectively identified historical precursors to digital and moving typography. For example, Andre and Girou regard Romain du Roi (1695) as the first instance of a bitmap typeface, as well as the originator of the concept of 'vectorial' fonts. ${ }^{9}$ This retrospective appreciation of historical developments, framing historical practices in contemporary contexts, depends on the complete understanding of those contemporary contexts. Since fluidity is a neglected category of temporal typography, ${ }^{10}$ and the subject of limited contemporary discussion, it is a practice that has not yet prompted reassessment of historical developments. Failure to identify fluidity has caused a lack of appreciation for the significance of some historical developments to contemporary practice. Although previous texts have sought to identify the origins of temporal typography in historical examples of static typography, such texts tend to address motion (a change in the position and layout of forms, on a global scale), rather than change that occurs at the local level of the individual letterform, as in fluid artefacts. Texts by Hillner and Ikonen are typical in identifying the influence of Futurist typographers such as F.T. Marinetti and, later, Concrete poets, as their typography sought to communicate temporal properties (such as rhythm) through static type, and most notably, 'analogy of motion'. ${ }^{11}$ The importance of the work of the Futurists and Concrete poets is undeniable, and so this article does not seek to revise these histories, however there are also several additional developments in static typography that must be added to these histories. Some developments in static typography, that have enabled fluidity in temporal typography, have been neglected by previous commentators. While Futurist typography can be said to share common features with 'type in motion', these similarities are most notable in overall (global) composition. It is with the relationship between letters that Futurists expressed temporality, not at a local level, with the characteristics of individual letterforms. While the style of an individual letter or character represents the qualities of a sound in some Futurist typography, progression of a temporal event was necessarily shown in Futurist work by distributing those characters across space. Temporality, therefore, is expressed by Futurist typography through global, not local, 
properties. Although there are many kinds of temporal typography that learn from Futurist typography and Concrete poetry, such as scrolling or dancing type, these artefacts tend to preserve the individual letter, with any change being applied to the overall layout. Fluidity is distinct from these other forms of temporal typography in that it is a change that occurs locally, affecting the individual letter. There have been other developments which focus on the individual letterform, which must be considered in seeking to identify the origins of temporal type exhibiting kineticism within individual letterforms, particularly the transformation of the form, as in fluid artefacts. The historical developments discussed here explore not the relationship between letters, but the form of each character, and in doing so provide a history that has not previously been associated with temporal typography.

\section{Romain du Roi and the transformable grid}

Histories of temporal typography, such as those referenced above, tend to omit reference to some influential developments in typography. Although, like Ikonen and Hillner, they acknowledge the significance of the experiments of Futurist and Concrete poets and typographers, they do not acknowledge the introduction of notions that are vital to fluid typography, such as the distortion or division of letterforms. While it is vital to acknowledge the influence of Futurism and Concretism, it is also important to consider the influence of the notion of the letter as a malleable form, as in experiments at the Académie des Sciences in the 1690s, which have not yet been explored in this context. Although the typeface that was developed by the Académie, Romain $d u$ Roi, is already considered notable as the first typeface to completely break free from type's origins in handwriting, ${ }^{12}$ I will attach particular significance to the process by which the slanted ('penché') form of each letter is achieved, emphasizing the method of production rather than the end-result. The development of the 'penche' form of Romain du Roi, specifically the distortions 
used to create its slanted forms, establish the notion that the silhouette of a letterform can be subjected to distortion.

In an effort to transform the process of type design from a craft into a science, and seeking to uncover the supposed secrets of the ideal letterform, a study conducted at the French Académie des Sciences from 1695 placed letterforms on grids. ${ }^{13}$ Inspired by the previous work of Geoffrey Tory (1529), the grid enabled letterforms to be skewed to produce italic versions. Typographers of the Académie viewed the creation of Romain du Roi letterforms as a 'rational' rather than 'intuitive' process. ${ }^{14}$ This established a connection between the 'creativity of the fine artist, and the logic of a scientist' in the pursuit of a mathematically designed typeface. ${ }^{15}$ A new typeface, intended solely for the use of the king, was developed within the grid. This new typeface, Romain $d u$ Roi, marked the transition from type as an extension of calligraphy, to type as a mathematically defined form, with roots in engraving rather than handwriting, and brought about 'a sudden change in the aesthetic of printing' $\cdot{ }^{16}$ Recent texts agree that the development of Romain du Roi established several notions that are now vital in the understanding and creation of typefaces: Andre and Girou retrospectively regard this use of the grid as the first instance of a bitmap typeface; ${ }^{17}$ They further propose, alongside Luc Devroye, that despite the presence of the grid, Romain du Roi may also be viewed as the originator of the concept of 'vectorial' fonts, as its letterforms were constructed from points which were then joined with lines and compass curves to create the contours of the letters. ${ }^{18}$ I propose that there is an additional and equally significant notion introduced by the work of the Académie, specifically, that Romain du Roi paved the way for distorted letterforms, and hence to fluidity in temporal typography.

The ultimate goal of the Académie des Sciences was to develop a product (the Romain du Roi typeface) rather than focusing on its production process. ${ }^{19}$ There is evidence, however, that the process by which the typeface was created was viewed by some as significant. Plates in 
Descriptions des Arts et Métiers, published decades later, in several volumes between 1761 and 1788, demonstrate the process of construction for each letterform (placed within a grid and alongside the circular outlines that are used to construct each letter) ${ }^{20}$ The presence of the grid in the plates published in Descriptions des Arts et Métiers indicates that the Académie considered the Romain du Roi innovative not only in its appearance, but in the method used in its design. It is this method that is reflected in contemporary fluid typography. It may be argued that, although the Romain du Roi is not an example of temporal typography, the method used in its creation (and the publication of that method) had a significant impact on the emergence of fluid type, where the audience is directly shown a character coming into being. When we consider that the aim of the Académie was to separate type from craft, establishing it as a mathematical product, the inclusion of the grid as a diagram acts as both illustration and evidence of the new method of production, and hence the new way of thinking about the nature of the letterform. Arguably, it is this process, rather than the end-product, that has been most influential in the later development of temporal typography, specifically in morphing letterforms. ${ }^{21}$

Significantly for this investigation into fluid typography, the committee created a slanted ('penché') version of Romain du Roi, by apparently 'deforming' the grid..$^{22}$ Although slanted and italic typefaces had previously existed, this was the first that was developed as an alternative version of an upright face, as opposed to an entirely separate typeface. ${ }^{23}$ This established the notion that a sloped letterform could be a manipulated version of an upright. ${ }^{24}$ By placing a letterform onto a grid, it was possible to stretch it to produce alternative weights, and to skew it in order to create slanted versions of a letterform. ${ }^{25}$ Slanted versions of Romain du Roi letterforms were achieved by tilting the vertical lines of the grid, and thus type could be considered, implicitly, and potentially, malleable. This ultimately introduced the notion that type, although static in print, has the potential to be manipulated. A single letter may, therefore, have multiple states, the forms of which are dictated according to the angle of the lines of the grid on which 
they are placed, and it may evolve into many new, visually distinct forms which have the same verbal identity. The notion of deforming a typographic character allows for three very important ideas in relation to fluid typography: firstly, that a single form can have multiple alternative states or appearances; secondly that those different states may exist within the same object/space but at different times; and thirdly that a form may be permanent without being fixed.

The notion of the letter as malleable is manifested in examples of metamorphosis in contemporary fluid typography, as illustrated in Komninos Zervos' typographic animation, Beer (2005). In this Flash animation, letterforms transform, morphing from one shape into another, each form presenting multiple letters as it evolves over time. Each letter distorts, while also gradually changing colour, until its silhouette is that of a different letter (see Fig. 1). Each form therefore has multiple, identifiable letter-identities, and also presents more abstract glyphs during transition from one letter to the next. Much like in the different versions of a single Romain $d u$ Roi character, each new state exists within a single form, having evolved over time so that it is a different state of the same form, not a separate form. Here, the characteristics of the morph are as effective as the words at communicating the meaning of the artefact, with languid metamorphosis reflective of the lethargic slur of drunken speech, or the stagger of the inebriated. 


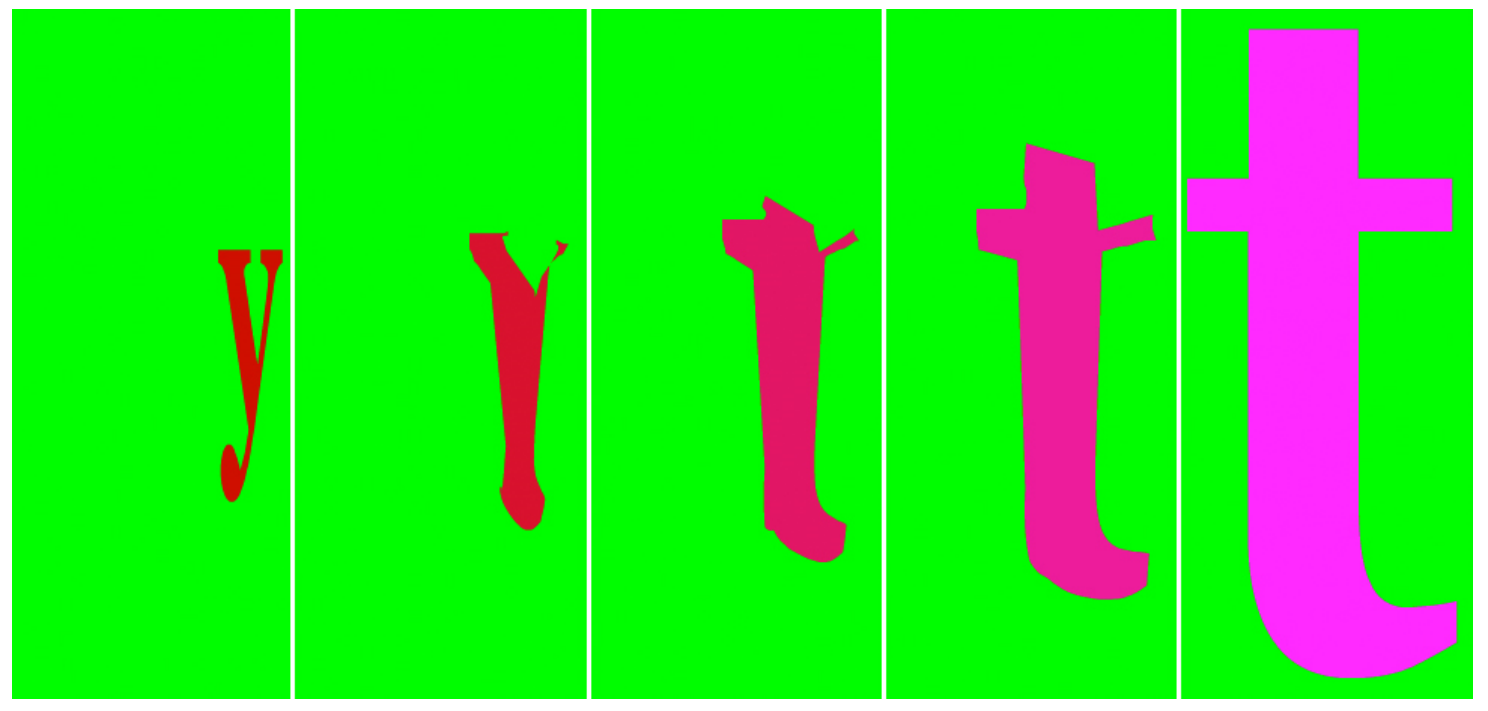

Fig. 1. An ' $y$ ' morphs into a ' $t$ ', producing several intermediary glyphs, in detail from

Komninos Zervos’ Beer, 2005. Source: Komninos Zervos, 'Cyberpoetry Underground’, Other Voices International Project 11 (2005), accessed July 13, 2011, http://www.othervoicespoetry.org/vol11/zervos/beer.html

Through observations of Louis Simmoneau's original plates of Romain du Roi characters (entitled 'Constructions des Lettres'), it is possible to identify yet another development that is significant to temporal typography. Contemporary commentators (including Jammes, Spiekermann, and Eskilson) suggest that the Académie's most significant achievements are the use of the grid and the resultant change in the aesthetic of the printed letter, ${ }^{26}$ but observations of Simmoneau's original plates reveal that the creation of the 'penché' form of Romain du Roi introduced another significant notion, that of three-dimensional transformation. ${ }^{27}$ In Simmoneau's plates, showing letterforms on a slanted grid, a triangular shaded area appears to the right of each grid (see Fig. 2). ${ }^{28}$ This shaded area implies a shadow cast by the plate onto a surface that is positioned behind and slightly away from the grid, as if the plate was propped up against a vertical wall. Perhaps more significantly, this shadow is a different shape to those shown alongside the upright grids. Here the shadow narrows at the top, indicating that the grid is leaning backwards, receding, 
whereas in plates showing the standard forms, the shadow is a consistent width, indicating that the grid is upright. The shadow could therefore arguably be interpreted as indicating the presence of depth that does not exist in the upright forms.

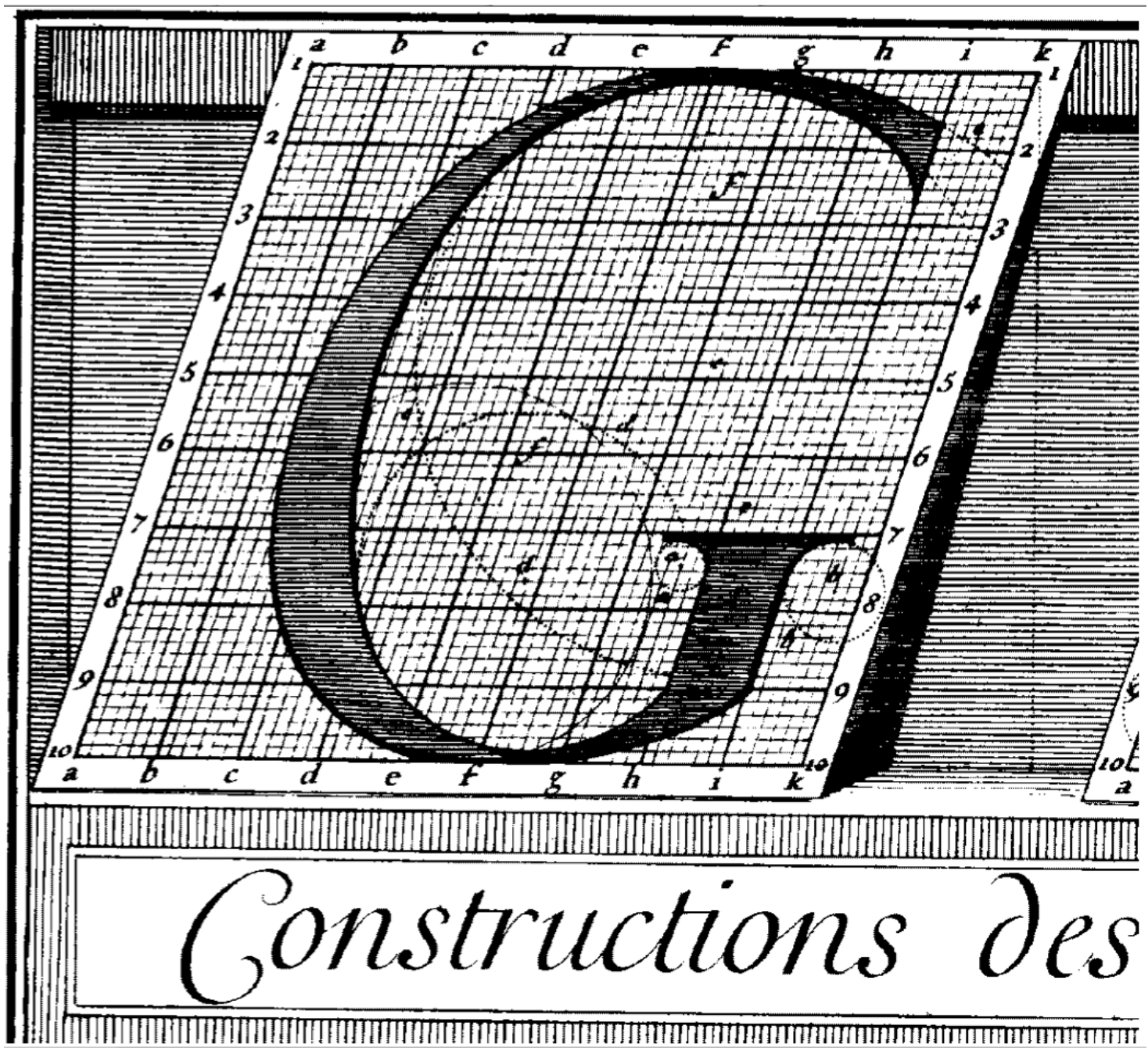

Fig. 2. Simmoneau (engraving) and S. Truchet (design), the letter ' $G$ ' as depicted in Constructions des Lettres, cartoons of Romain du Roi penché, 1716, published in Descriptions des Arts et Métiers, 1761 - 1788. The grid appears to slope backwards, as if the top of the grid were isometrically receding. Source: Andre and Girou, 'Father Truchet,' 11. 
If this shadow can be understood as representing depth, then here is evidence to suggest that recent texts have failed to identify its significance, and have misinterpreted the production method of the 'penché' letterforms. Andre and Girou, and Rigby, interpret the French 'penché' as 'slanted' or 'italic', suggesting two-dimensional manipulation, not three-dimensional transformation. ${ }^{29}$ Only Jammes uses the term 'sloped', perhaps implying three-dimensional shift (though his text does not explicitly refer to depth or volume). ${ }^{30}$ Andre and Girou suggest that Simmoneau's plates show the apparent 'deformation' of Romain du Roi in order to achieve the 'penché' form of each letter. ${ }^{31}$ Even in its native French, the term 'penché' is vague, in that it can be understood either as two-dimensional slanting or three-dimensional leaning or sloping. ${ }^{32}$ As can be observed in the reproduction below (Fig. 2), the horizontal lines of the grid remain horizontal, while vertical lines slant to the right, thereby repositioning the top of the grid (and the letter contained within it), further right than the bottom. This grid, viewed alone, could justifiably be described as deformed, as it has been by Andre and Girou. ${ }^{33}$ However, to the right of this slanted grid is a triangular shadow, indicating that the grid is not skewed to the right, but is in fact sloped backwards, so that the top of the letter recedes in isometric three-dimensional space. These diagrams suggest that the letterforms are not in fact deformed or skewed, but retain their original shape. The apparent slanting of the letter is an optical illusion achieved through transformation of the letter plane in illusionistic space.

It may be that this framing is not considered noteworthy by recent texts because these plates were produced when such framing was commonplace in France, as well as the rest of Europe and the USA. It was common to present typographic information within an ornamental frame, as in map cartouches, from the twelfth until the middle of the nineteenth century. ${ }^{34}$ Such cartouches often positioned typographic elements within a three-dimensional environment. Although many positioned text within ornamental pictorial settings which appeared entirely removed from the process of creating or presenting type or writing, many such cartouches presented text on a scroll, 
or as if engraved on a slab of stone, thereby directly illustrating ways in which equivalent words could be displayed in real-life settings. These emphasized three-dimensionality, with shaded areas and highlights. In many late examples, even the type itself was presented as three-dimensional, with shading beneath each letter (see below). ${ }^{35}$ In a few cases, the lettering was even distorted to complement the shape of the surface on which it apparently sat. Cartouches from Didier and Gilles Robert de Vaugondy's Atlas Universel (1757) feature lettering that is distorted as if sloping away from the viewer, much as it does in Simmoneau's engravings. The de Vaugondys' cartouche depicts lettering positioned on a rock with a receding surface. The slanting of the letterforms is, therefore, not a feature of the letter, but an indication of the angle of the surface on which the lettering sits. Further cartouches in the same Atlas show other distortions of letterforms, apparently caused by the shape of the surface on which they appear. Given such examples, it would be reasonable to suggest that the apparent slope depicted in Simmoneau's engravings, and not a deformation of the grid, can be understood as being responsible for the slanting of the Romain du Roi letters.

As Jammes observes, the notion of the italic or slanted Roman is in itself 'revolutionary', but the imagined sloping of the letterform, so that it recedes in virtual three-dimensional space, may be considered even more significant, particularly since three-dimensional typefaces did not come into common use until more than 100 years later (see below) ${ }^{36}$ There is, however, a fundamental difference between three-dimensional type and the three-dimensional relocation of a single plane. Simoneau's 'Constructions des Lettres' do not translate the planar letter into a three-dimensional form, but they do, as the presence of the shadow suggests, imagine it as existing within threedimensional space. This implies a fundamental shift in the understanding of the nature of the space occupied by a letter, replacing the idea of the flat page with the notion of the letter as an object within space. As an object, the letter may be viewed from multiple angles, slanted or rotated, and so may apparently distort without undergoing any actual manipulation. 


\section{Nineteenth century three-dimensional lettering}

Further progress towards contemporary fluid typography was made via the introduction of threedimensional typography. The conventional or customary appearance of written or printed characters is as two-dimensional forms. ${ }^{37}$ As Skolos and Wedell observe, 'Letterforms themselves have no intrinsic third dimension', ${ }^{38}$ However, letters have been depicted as three-dimensional objects for many years. It is difficult to identify precisely when three-dimensional type first emerged since, as a small survey of typefoundry catalogues from the nineteenth century reveals, foundries rarely published the dates of the release of their typefaces. ${ }^{39}$ Eskilson observes that three-dimensional typefaces flourished from the 1850 s. ${ }^{40}$ However, earlier specimens demonstrate that the concept of the verbal form as a three-dimensional object was well established in the preceding years, first in hand-drawn lettering, and then in type. ${ }^{41}$ In illuminated letters, signage, and illustrated lettering, letterforms have been depicted either as composed of objects, or as objects themselves. ${ }^{42}$ Although typefoundry catalogues omit dates, a few dated specimens have been preserved and remain in more recent encyclopaedias of type. J.F. Rosart's Enschedé, produced in 1759, includes partly 'shaded capitals' that are 'almost three-dimensional in appearance' ${ }^{43}$ Enschedé's capitals contain shaded areas to the right of each stroke, as if illuminated from the left. However this shading is omitted from some strokes and serifs, suggesting that the three-dimensional appearance is incidental. Fully three-dimensional forms began to emerge in the 1810s and 20s. Thorne Shaded (Robert Thorne, c. 1810), uses similar shading to Enschedé, but extends it to all strokes and serifs, creating the impression of type which has been extruded. Vincent Figgins' 1817 Egyptian typeface extends the notion of the character as an object by extruding only its contours. Egyptian presents the front and side surfaces that one would encounter in any three-dimensional object, with the addition of internal surfaces, thus multiplying the potential surfaces that could be imagined as contained within the character. There 
is the possibility of imagining each form as viewed from within the centre of the character, looking outwards at its contours as if they were the walls of an enclosed space. In Egyptian, ambiguity of figure and ground exists as the apparent front faces of each letter bear no ink, and so are not printed on the page. The existence of these front surfaces is thereby not directly depicted, only assumed on the basis of cues from the surrounding form. This illusion occurs as a consequence of the Gestalt law of Prägnanz, which suggests that we are more likely to perceive the geometrically simple shape of a letter than a group of many more complex forms that, in this case, represent each vertical surface. By presenting the character as an object, these examples imagine the character as having tactile properties, such as surface texture and weight. Crucially for this investigation into fluid typography, three-dimensional type introduces the idea that a character may have multiple surfaces. By extension, the character can be imagined as existing in navigable space, and that the viewer could approach those multiple surfaces from different directions.

The notion of a verbal form as a three-dimensional object is distinct from the notion of a verbal form as occupying three-dimensional space. Though, as was argued above, the italic form of Romain du Roi implies the presence of depth within the page, the characters are themselves planar. The apparently three-dimensional lettering of the nineteenth century reverses this, with three-dimensional characters existing on a flat plane. The treatment of characters as objects allows viewers to imagine them as 'physical, spatial entities', with the potential to be viewed from alternative angles. ${ }^{44}$ These nineteenth-century three-dimensional typefaces depict the extrusion of flat characters, exploring 'illusionistic depth' ${ }^{45}$ Vital to this exploration of fluidity is that this extrusion of a flat character imagines it as having multiple surfaces, with only the front surface of each three-dimensional object having the shape of a character while other faces are abstract, and not identifiable as alphanumeric. The side surfaces of an 'A' or 'B', for example, all appear to be rectangles, and the alphabetic identity of the form is only revealed if the viewer is 
presented with what is considered to be the front surface (as in Fig. 3). Potentially, therefore, a three-dimensional character is capable of containing and presenting multiple different identities. Although early three-dimensional characters are drawn to display the alphanumeric front face, the 3D character can be imagined as capable of displaying numerous non-verbal identities when viewed from another angle.
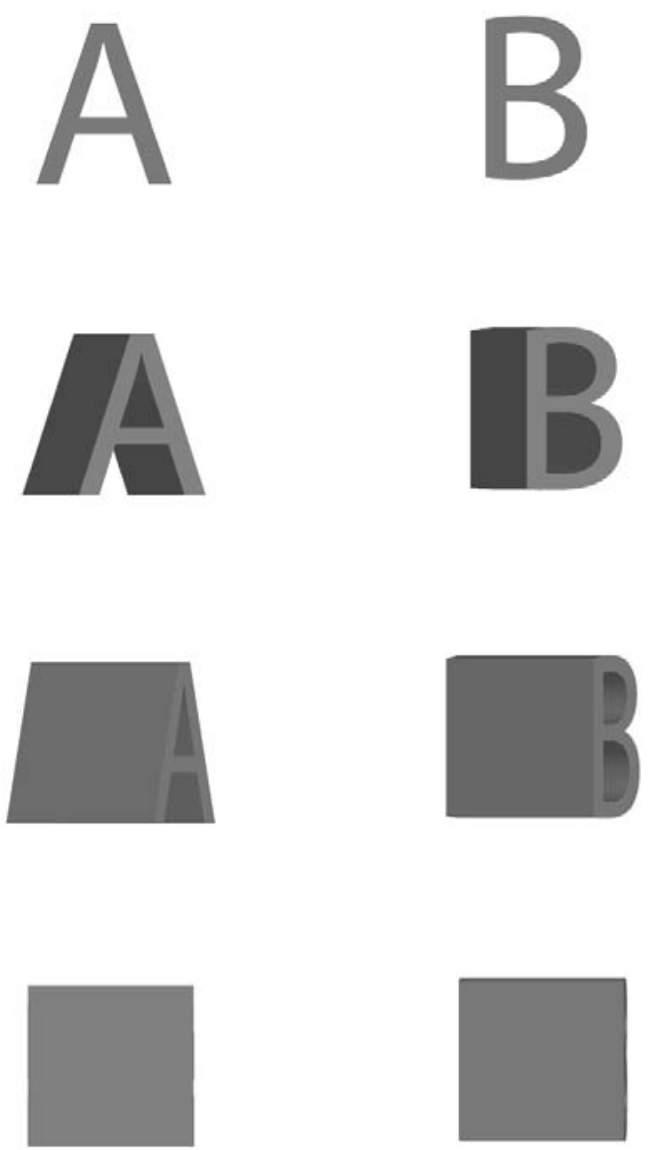

Fig. 3. An extruded 'A' and 'B' show that, when rotated, the verbal identity may be hidden, and alternative surfaces are revealed. These other surfaces may appear to have a different identity. Both the ' $A$ ' and ' $B$ ', when viewed from the side, appear to be identical abstract squares. 
This suggestion that the letter may be an object, with multiple surfaces, allows for the possibility that different surfaces may contain different forms, each with a different identity. As demonstrated by Bart Overley’s Ligature (1995, Fig.4), the side faces of a three-dimensional letter object may be more complex than those of an extruded letterform, and may even present an alternative verbal identity. Here, each object 'has alternate readings from different perspectives' ${ }^{46}$ Overly presents both ' $A$ ' and ' $B$ ' in the same object. When viewed directly from above, an ' $A$ ' form is visible, but when viewed from either side, ' $\mathrm{B}$ ' is presented. In this way, a single object can have multiple letter-identities. Though Overly's virtual models are not intended for consumption in temporal environments, this object demonstrates the possibility of presenting a number of alternative verbal identities within a single three-dimensional object. Many of the objects presented in fluid artefacts have similar properties, allowing fluidity when displayed in a temporal environment. 


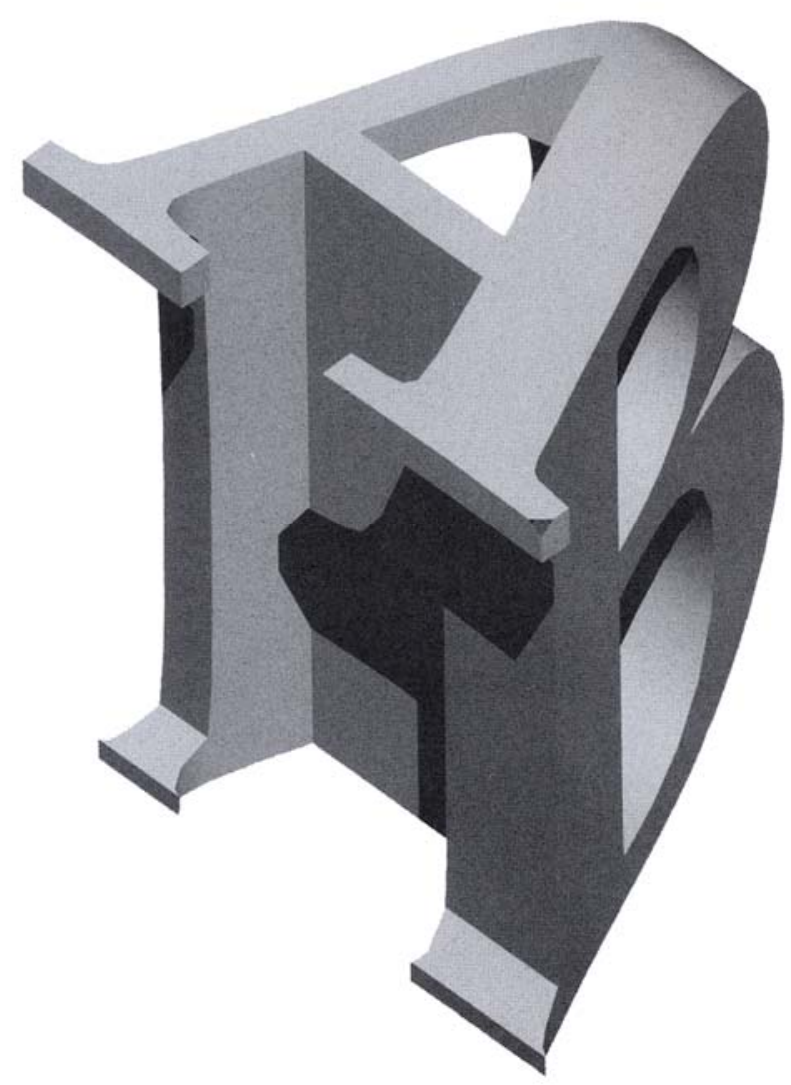

Fig. 4. Bart Overly, Ligature, 1995. This object contains several verbal identities which exist simultaneously, and could be revealed by rotation of the object. Source: Miller, Dimensional Typography, 55.

In a temporal or navigable environment, the various surfaces, and hence the various identities, may be revealed over time. As each surface is revealed, the object appears to acquire a new identity. In Vincent Viriot's Evil/Love/Hate (2008, Fig. 5). Viriot also presents a threedimensional virtual model which contains three different verbal identities. As the film progresses, the camera navigates around the model to sequentially reveal the words 'hate', 'evil', and 'love'. Each object, being three-dimensional, has several surfaces. Some of these surfaces are illuminated with an apparently blue light, others with a pink light, and others are left unlit. Those 
surfaces which are unlit remain the same white as the backdrop, allowing for each object to appear noticeable when viewed from its coloured/illuminated side, but to blend into the background when its undecorated surfaces are presented. As the camera swings in a loop around the arrangement of objects, each of the four structures presents, in turn, one of the four letters of each word. The differently coloured surfaces help to differentiate between the different verbal identities, while the undecorated surfaces allow for an apparent reduction in the number of strokes when the same object must present, for example, the three strokes of an ' $\mathrm{A}$ ', in 'hate' and then the single stroke of an 'I' in 'evil'.
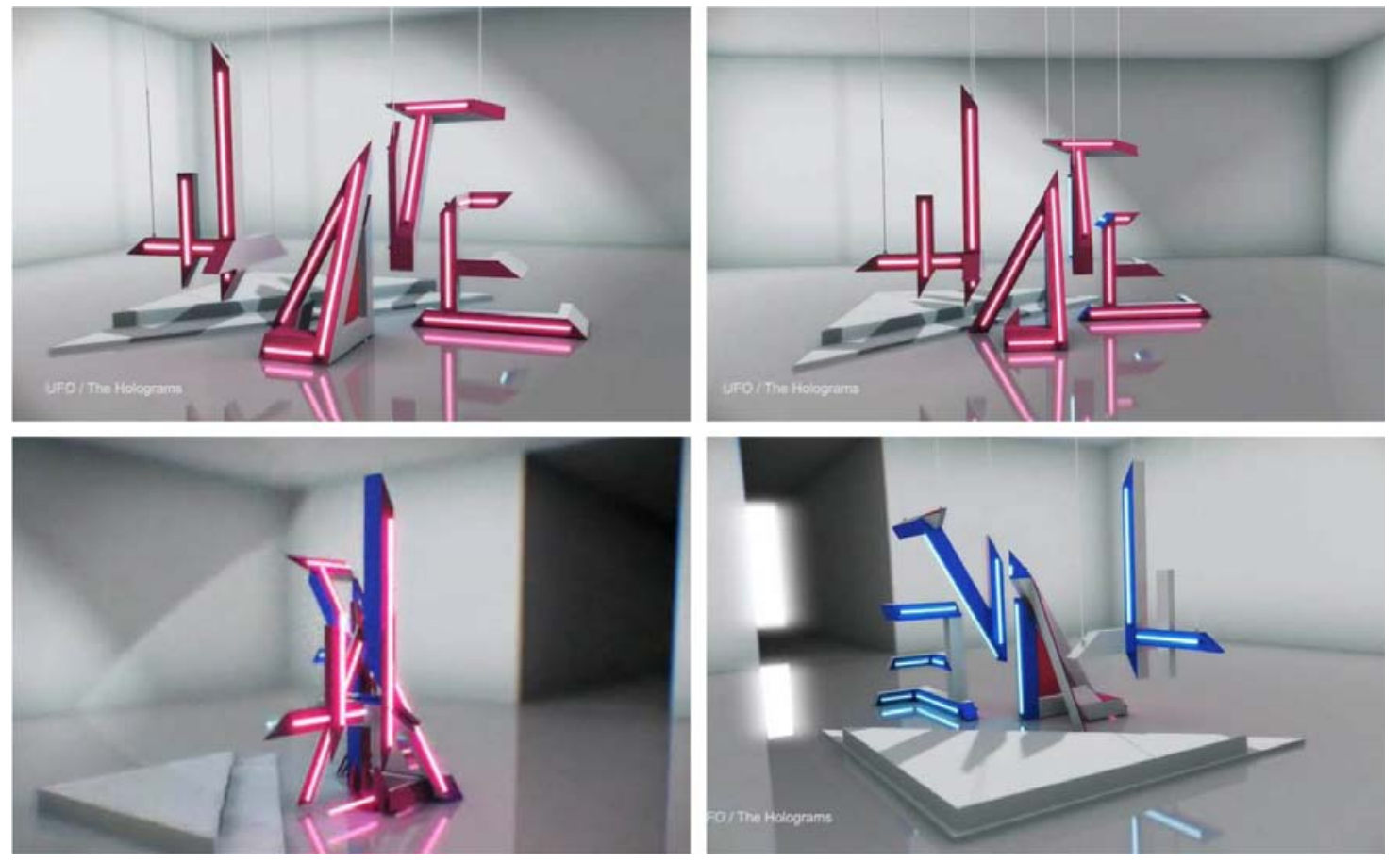

Fig. 5. Vincent Viriot, Evil/Love/Hate, 2008. Source: Vincent Viriot, 'Evil/Love/Hate,' Behance, 2008, accessed July 18, 2011, http://www.behance.net/fmk_7/Frame/145974

\section{The modular lettering of Theo van Doesburg, Bart van der Leck and Josef Albers}

Modular lettering of the modernist era introduced two notions that are vital in enabling some fluid behaviours: firstly that the verbal form may be constructed from component parts; and secondly 
that those parts may serve multiple roles, as type and as image. Fundamental to some fluid behaviours is the suggestion that type can be constructed from smaller components, or 'primitives', as in 'modular' lettering. ${ }^{47}$ Modular lettering became particularly prominent in modernist typographic practice, including Josef Albers' Stencil (1925) Theo van Doesburg's lettering for De Stijl magazine (1917), and Bart van der Leck’s lettering for works including Het Vlas (1941). These works reflected modernist enthusiasm for regular and interchangeable component parts. The modernist era was a time of 'mass production and prefabrication', made possible through the 'standardisation of components...for the rapid erection and repair of objects' ${ }^{48}$ It was possible to emulate the machine aesthetic through repetition, enhanced by the reductionism that was practiced, in particular, at the Bauhaus. ${ }^{49}$ These ideas led to verbal forms being broken down into their most primitive components, resulting in characters that were not complete wholes, but configurations..$^{50}$ Each character was not a single form, but a collection of geometric parts, often with gaps between them to emphasize the modularity.

As design historian Paul Greenhalgh observes, 'the Modern movement was concerned almost wholly with means of production rather than with consumption'. ${ }^{51}$ The construction of the character - how it was produced - was an important consideration for typographers including Albers and van Doesburg. Although their methods may have been very different to those of the Académie des Sciences, these practitioners embraced the same notion that the process of production could be considered at least as important as the outcome. ${ }^{52}$ In 'modular construction', this process is one of building or assembly. ${ }^{53}$ In his Horseman poster (1919), Bart van der Leck constructed characters from assorted rectangular forms. Van der Leck himself referred to such works as 'compositions', describing characters that are built, as opposed to moulded, with each character 'systematically' constructed 'as if it were a building' ${ }^{54}$ Construction, as opposed to other methods of creation, leaves the component parts as whole forms or objects in their own 
right: part of a verbal character but still independent. The forms may still be identified as rectangles, even after they have been stacked to create the shape of a verbal character.

Central to these modular letterforms is the notion that component parts are interchangeable. Only a limited number of primitives are used to construct the entire alphabet. In Albers' Stencil, only three geometric 'primary forms', rotated, stacked and rearranged, are required to construct every one of the 26 letters and numbers in a standard character set, while van Doesburg's De Stijl requires only four rectangles of assorted lengths. ${ }^{55}$ It was fundamental, in order to adhere to modernist principles, that variation among component parts was minimal. Mass production requires parts that are 'capable of adaption', so a single component part can be put to use in multiple different roles. ${ }^{56}$ As Stencil demonstrates, this notion is applicable in typeface design. One of Stencil's primary forms, the tall rectangle, may, for example, serve as the stem of a ' $\mathrm{D}$ ' or a ' $T$ '. Conceived as a configuration of interchangeable primitives, the verbal character is capable of being dismantled and reassembled. One character may be dismantled, and its component parts used to construct another character.

Van Doesburg and van der Leck are among those in the De Stijl movement who 'sought to unite' various artistic forms, including painting and typography. ${ }^{57}$ Van der Leck’s book of fairy tales, Het Vlas (1941), contains type and images that are similarly 'fragmented' ${ }^{58}$ A blending of the pictorial and the verbal occurs as lettering appears directly alongside, and often aligned with, abstract forms. The typefaces that appear in Theo van Doesburg's cover, and in Het Vlas, are 'typefaces built out of the principles of De Stijl painting' $\cdot{ }^{59}$ In using the same primitives to construct typographic and pictorial arrangements, these designers made progress towards the creation of a universally useful palette of primitives, transcending the divide between the various forms of art and design. Verbal and pictorial languages are considered in the same terms. At least at the point of production, these two modes of communication are no longer distinct. As Massin 
observes, van Doesburg’s pictorial shapes are 'as disjointed and steady as letters' ${ }^{60}$ De Stijl practitioners asserted that the use of similar geometric forms throughout the typographic and pictorial elements of a work would promote 'harmony' ${ }^{61}$ Van Doesburg was among those who proposed that, by transcending the divide between established fields of design practice, a universal and therefore 'pure' outcome could be achieved. ${ }^{62}$

As can be observed in Theo van Doesburg's cover for the first edition of De Stijl magazine (1917), and Bart van Der Leck’s poster for Delft Salad Dressing (1919, Fig. 6), demonstrate a remarkable similarity between the primitives used to construct type, and those used to construct image. Components of letterforms are similar, or in some cases identical, to the components of images and abstract pictorial arrangements. In van Doesburg’s cover, the same black rectangles are used in the construction of verbal forms as are used in the construction of the abstract pictorial arrangement which appears beneath. Being interchangeable, these rectangles do not have a fixed typographic identity. If each block may be exchanged for another, so, too, can its identity be replaced, with each rectangle having the potential to serve as both image and type. ${ }^{63}$ An image may be dismantled in order to provide the component parts of a typographic sequence, and a verbal character may be dismantled and rearranged to form a part of an image; a process that is exhibited in the behaviours of many contemporary examples of fluid typography. In van Doesburg's De Stijl design, the same primitives are used in the construction of letterforms as are used in the construction of the abstract pictorial arrangement which appears beneath. Bart van Der Leck’s poster for Delft Salad Dressing (1919) also demonstrates a remarkable similarity between the primitives used to construct type, and those used to construct image (Fig. 6). A figurative image is reduced to coloured polygons, with similar polygons used to create type. The addition of colour to the type reinforces the pictorial quality of the blocks that are used in the construction of van der Leck’s lettering. 


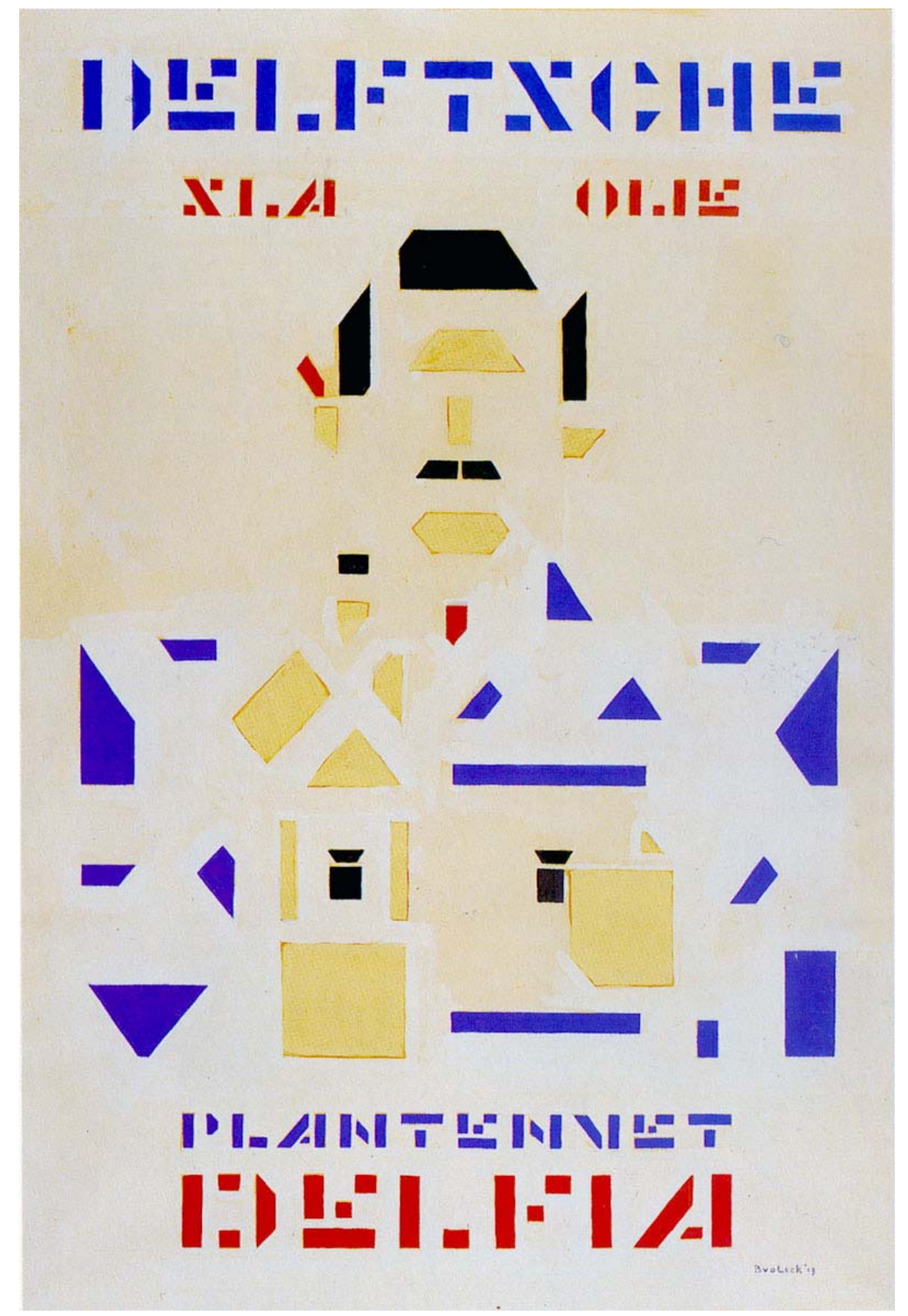

Fig. 6. Bart Van der Leck, poster for Delft Salad Dressing, 89x59.9cm, 1919. Source: J.

Tylor Flatt, 'Bart Antony Van Der Leck: Delft Salad Oil,' Retained, 2009, accessed July 13, 2011, http://retained.blogspot.com/2009/06/bart-anthony-van-der-leck-delft-salad.html 
The basic unit of each of these arrangements is a regular, and notably non-typographic form. ${ }^{64}$ Although each entire configuration may act as a letterform, the identity of each individual form, as a rectangle, remains. Identities are not mutually exclusive. Within the same configuration, multiple identities are perceived: at a micro level, there are rectangles (pictorial forms), and at a macro level, there is lettering. Each configuration thereby operates pictorially at a micro level, and verbally at a macro level. These multiple identities, contained within a single configuration, communicate two distinct messages at the local and global levels. The individual components are abstract, pictorial; while the whole configuration takes on additional verbal significance. This is also seen in contemporary examples of fluidity, in which characters are constructed over time from objects that are initially perceived as having non-verbal identities.

Martin Lambie Nairn’s first Channel 4 idents, produced from 1982 onwards, and the later Atlas idents by The Moving Picture Company (MPC, 2004-2010), show the construction of the Channel 4 ident from separate parts. These separate parts initially appear to be objects in their own right. In Lambie Nairn's early idents, the figure ' 4 ' is constructed from abstract polygons, which move independently of one another and align to present a group that can be read as a single figure. MPC was employed to retrieve some of the core characteristics of Lambie Nairn's processes, while introducing new features to demonstrate the radical change that had come about as a consequence of the introduction of 'the arrival of many new digital channels' ${ }^{65}$ The Atlas idents present similar construction behaviour to Lambie Nairn's idents, but incorporate significant visual difference with the addition of figurative objects, digitally modelled to imitate live-action footage. In these idents, the component parts of the ' 4 ' are 'subtly disguised as elements in each environment shown' ${ }^{66}$ In one example, Tokyo (2006, see Fig. 7), objects initially appear to be illuminated street signs, but, through tracked navigation, resulting in a parallax, these objects appear to align, adopting the identity of the figure ' 4 '. During this process, the initial identity of each object is revealed to be a masquerade. Although they initially appear to 
be pictorial, and part of live-action footage, through fluidity they are cast out of that paradigm and into one of motion graphics. The construction of the ' 4 ' forces a sudden shift from an apparently environmental space, to a graphical space.
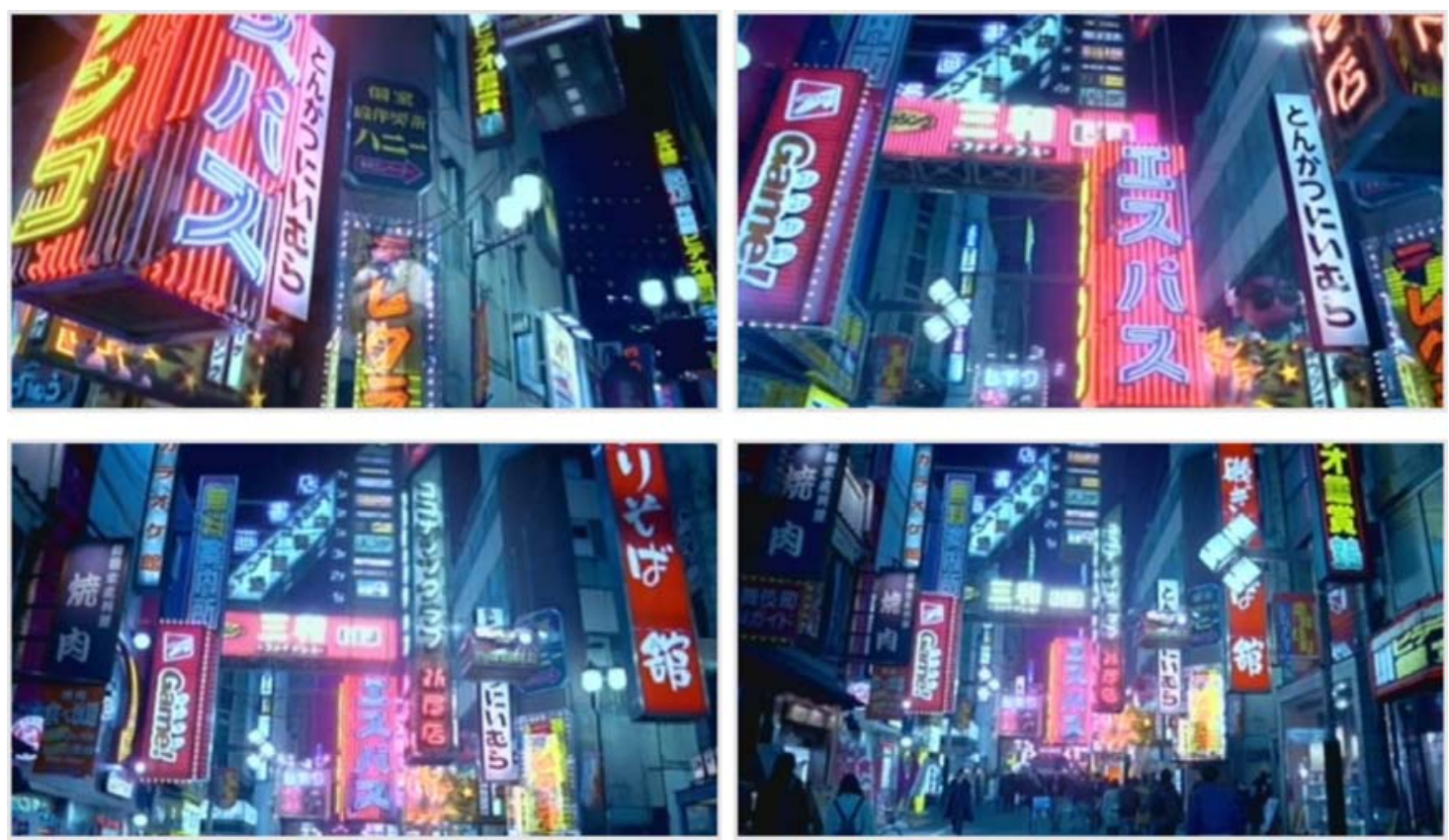

Fig. 7. MPC, Tokyo, 2006. In MPC’s idents, the '4' is constructed from apparently environmental objects. These objects appear to be part of the landscape until they apparently align to construct the '4'. Source: MPC, 'Channel 4 Idents,' The Moving Picture Company, 2006, accessed July 17, 2011, http://www.movingpicture.com/index.php?option=com_content $\&$ view=article\&id=341\&catid=38\&Itemid=926

\section{Conclusion}

The fluid behaviours that are seen in some contemporary temporal typography are dependent on qualities and notions that were established in print. Much writing on the origins of temporal typography cites historical examples that present 'analogy of motion' ${ }^{67}$ However, it is important to acknowledge that it is not just motion that is exhibited in temporal typography. This article has 
observed that other kinds of motion and change occur within individual forms, including elasticity and fluidity. The increasing ubiquity of this kind of kineticism demands additions to existing histories, with emphasis on the processes by which a letter may come into being. This amended history, as established in this article, identifies developments that did not aspire to motion, but rather to the letter as a more complex form than a single or flat sign. Developments that occurred in the seventeenth, nineteenth and twentieth century established precedence for fluidity. Although the temporal media that make fluidity possible were not available until the twentieth century, the three notions outlined above were vital in allowing contemporary practitioners to exploit new technology to a greater extent than if they had understood the letterform only as a fixed and flat sign. 


\section{Declaration}

This paper is based on ideas from a PhD thesis supervised by Grace-Less Maffei, an editor at the Journal of Design History.

\section{List of Figures}

Fig. 1 An 'y' morphs into a 't', producing several intermediary glyphs, in detail from Komninos Zervos’ Beer, 2005. Source: Komninos Zervos, ‘Cyberpoetry Underground’, Other Voices International Project 11 (2005), accessed July 13, 2011, http://www.othervoicespoetry.org/vol11/zervos/beer.html

Fig. 2 L. Simmoneau (engraving) and S. Truchet (design), the letter ' $G$ ' as depicted in Constructions des Lettres, cartoons of Romain du Roi penché, 1716, published in Descriptions des Arts et Métiers, 1761 - 1788. The grid appears to slope backwards, as if the top of the grid were isometrically receding. Source: Andre and Girou, 'Father Truchet,' 11.

Fig. 3 An extruded 'A' and 'B' show that, when rotated, the verbal identity may be hidden, and alternative surfaces are revealed. These other surfaces may appear to have a different identity. Both the ' $\mathrm{A}$ ' and ' $\mathrm{B}$ ', when viewed from the side, appear to be identical abstract squares.

Fig. 4 Bart Overly, Ligature, 1995. This object contains several verbal identities which exist simultaneously, and could be revealed by rotation of the object. Source: Miller, Dimensional Typography, 55.

Fig. 5 Vincent Viriot, Evil/Love/Hate, 2008. Source: Vincent Viriot, ‘Evil/Love/Hate,’ Behance, 2008, accessed July 18, 2011, http://www.behance.net/fmk_7/Frame/145974 
Fig. 6 Bart Van der Leck, poster for Delft Salad Dressing, 89x59.9cm, 1919. Source: J. Tylor

Flatt, ‘Bart Antony Van Der Leck: Delft Salad Oil,’ Retained, 2009, accessed July 13, 2011, http://retained.blogspot.com/2009/06/bart-anthony-van-der-leck-delft-salad.html

Fig. 7 MPC, Tokyo, 2006. In MPC’s idents, the '4’ is constructed from apparently environmental objects. These objects appear to be part of the landscape until they apparently align to construct the '4'. Source: MPC, 'Channel 4 Idents,' The Moving Picture Company, 2006, accessed July 17, 2011, http://www.movingpicture.com/index.php?option=com_content\&view=article\&id=341\&catid=38\&Itemid=926

\footnotetext{
${ }^{1}$ Y.Y. Wong, 'Temporal Typography: characterization of time-varying typographic form', MS thesis, MIT, 1995, $<$ http://hdl.handle.net/1721.1/29102> accessed 19 July 2011; Y.Y. Wong, 'Temporal typography: A Proposal to Enrich Written Expression,' CHI 96 Conference Proceedings, 1996, < http://acm.org/sigchi/chi96/proceedings/videos/W ong/yyw_txt.htm > accessed 13 July 2011.

2 E. Kac, 'Key Concepts of Holopoetry.’ Electronic Book Review, 3 January1997

<http://www.electronicbookreview.com/thread/electropoetics/uncontrollable> accessed 16 July 2011, originally published in D.Jacksin, E. Vos, \& J.Drucker (eds), Experimental-Visual-Concrete: Avant-Garde Poetry Since the 1960, Rodopi, Amsterdam-Atlanta: 1996, pp. 247- 257. See my previous explorations for more details of how Kac’s terms can be applied in temporal typography: ‘Fluid Characters in Temporal Typography,' Fusion, vol. 1. Issue 1, 2012; 'The Behaviours of Fluid Characterforms in Temporal Typography', PhD Thesis: University of Hertfordshire, 2012; 'Fluid Typography: Type Meets Image in Temporal Media', Writing Design: Object, Process, discourse, Translation, Annual Design History Society conference, University of Hertfordshire, 3-5 September 2009; 'Fluid Typography: Defining a New Form of Temporal Typography', New Views 2: Conversations and Dialogues in Graphic Design, London College of Communication, 9-11 July 2008.

${ }^{3}$ M. Woolman \& J. Bellantoni, Type in Motion: Innovations in Digital Graphics, Thames \& Hudson, London,1999; J. C. Lee, Jodi Forlizzi, \& S. E. Hudson, 'The Kinetic Typography Engine: An Extensible System for Animating Expressive Text,' Proceedings of the 15th annual ACM Symposium on User Interface Software and Technology, 2002, pp. 81-90, $<$ http://johnnylee.net/kt/dist/files/Kinetic_Typography.pdf > accessed July 13, 2011.

${ }^{4}$ G. L. Shaw \& V. S. Ramachandran, 'Interpolation during apparent motion’, Perception, vol. 11, no. 4, 1982, p. 491.

${ }^{5}$ Kac, op. cit.

${ }^{6}$ T. Gaze, Asemic Movement vol. 1, January 2008, p. 2,

$<$ http://vugg.wippiespace.com/vugg/gaze/asemicmovement1.pdf> accessed 13 July 2011,

7 'Fluid Characters in Temporal Typography,' Fusion Vol. 1. Issue 1, 2012; 'The Behaviours of Fluid Characterforms in Temporal Typography', PhD Thesis: University of Hertfordshire, 2012;

8 J. Abbott Miller, Dimensional Typography, Princeton Architectural Press, New York, 1996, p. 5-6.
} 
9 J. Andre \& D. Girou, 'Father Truchet, the Typographic Point, the Romain du Roi, and Tilings', TUGboat 20, no. 1, 1999, p. 10, accessed 13 July 2011, http://www.tug.org/TUGboat/Articles/tb20-1/tb62andr.pdf

${ }^{10}$ Existing surveys of temporal typography tend to neglect to make the distinction between motion and other kinds of change. I have written at length elsewhere about the failure to identify transformation, and hence fluidity, in temporal typography, most extensively in 'The Behaviours of Fluid Characterforms in Temporal Typography', PhD Thesis: University of Hertfordshire, 2012.

${ }^{11}$ M. Hillner, 'The poetics of transition: the ambiguous characteristics of virtual typography', MPhil thesis, Royal College of Art, 2007; T. Ikonen, 'Moving Text in Avant-Garde Poetry: Towards a Poetics of Textual Motion,'

Dichdung-digital.de, vol. 4, no. 30, 2003, < http://www.brown.edu/Research/dichtung-

digital/2003/issue/4/ikonen/index.htm> accessed 13 July 2011,

12 E. Spiekermann, 'The Stroke', review of The Stroke by Gerrit Noordzij, Hyphen Press Journal, 26 September 2006, $<$ http://www.hyphenpress.co.uk/journal/2006/09/26/stroke_spiekermann_review>accessed 13 July 2011.

${ }^{13}$ R. Dodd, From Gutenburg to Opentype, Illex, Eadt Sussex, 2006, p. 44; See plates reproduced in A. Jammes,

'Académisme et Typographie: The Making of the Romain du Roi', Journal of the Printing Historical Society Vol. 1

(1965); H. B. Higgins, The Grid Book, MIT Press, Mass, 2009, p. 190; Jammes, op. cit., p. 76

${ }^{14}$ S. J. Eskilson, Graphic Design: A New History, Laurence King, London, 2007, p. 19.

15 Ibid.

${ }^{16}$ S. Morison, The Typographic Arts, London, 1949, pp. 27 and 59, as cited in Jammes, op. cit., p. 79; Ibid.

17 J. Andre \& D. Girou, 'Father Truchet, the Typographic Point, the Romain du Roi, and Tilings', TUGboat Vol. 20 , no. 1, 1999), p. 10, accessed 13 July 2011, http://www.tug.org/TUGboat/Articles/tb20-1/tb62andr.pdf

${ }^{18}$ Ibid.; L. Devroye, 'Formatting Font Formats'. TUGboat, vol. 24, no. 3, 2003, p. 590,

$<$ http://www.tug.org/TUGboat/Articles/tb24-3/devroye.pdf > accessed 19 July 2011,

${ }_{19}$ The typeface was intended for practical use without the grid, as in its first appearance in: De L'imprimerie Royal,

Medailles sur les principaux evenements du regne de Louis le Grand, Avec des Explications Historiques, Paris, 1702.

${ }^{20}$ Andre \& Girou, op. cit., p. 11.

${ }^{21}$ Though these plates exhibit letterforms within the grid, drawing attention to the production process, letterforms are only displayed in their before and after states: upright and slanted. Without temporal environments, the process of typographic manipulation can only be described, not recorded.

${ }^{22}$ Andre \& Girou, op. cit., p. 10.

${ }^{23}$ Ibid.

${ }^{24}$ Ibid.

${ }^{25}$ J. Abbott Miller \& E. Lupton, ‘A Natural History of Typography’, in Looking Closer: Critical Writings on Design, ed. M. Bierut, Allworth Press, New York, 1994, p. 21.

${ }^{26}$ Jammes, op. cit., p. 71-95; E. Spiekermann, 'The Stroke’, Review of The Stroke by Gerrit Noordzij. Hyphen Press Journal, (26 September, 2006), <http://www.hyphenpress.co.uk/journal/2006/09/26/stroke spiekermann review> accessed 13 July 2011; Eskilson, op. cit., p. 18.

${ }^{27}$ Ibid.

${ }^{28}$ Plates reproduced in Jammes, op. cit., p. 71-95.

${ }^{29}$ Andre \& Girou, op. cit. p. 11; S. Rigby, 'An Unbearable Lightness?' Visual Communication, vol. 6, no. 3, 2007, p. 288, <http://vcj.sagepub.com/cgi/reprint/6/3/281.pdf > accessed 13 July 13, 2011,

${ }^{30}$ Jammes, op. cit. p. 85.

${ }^{31}$ Andre \& Girou, op. cit., p. 11.

${ }^{32}$ Since French is not the native language of the author, this thesis document primarily responds to English interpretations of the term 'penché', rather than how it may be interpreted by native French speakers.

${ }^{33}$ Ibid.

${ }^{34}$ E. Lynam, The Mapmaker's Art, Batchworth Press, London, 1953, p. 48.

${ }^{35}$ See examples at D. Rumsey, 'Cartouches or Decorative Map Titles,' David Rumsey Map Collection, 2010, <http://www.davidrumsey.com/blog/2010/2/25/cartouches-decorative-map-titles>accessed 13 July 13 2011,

36 Jammes, op. cit., p. 85.

${ }^{37}$ N. Skolos \& T. Wedell, Type, Image, Message: A graphic design layout workshop, Rockport, Gloucester, MA, 2006, p. 10.

${ }^{38}$ Ibid.

${ }^{39}$ W. Pincus Jaspert, W. Turner Berry, \& A. F. Johnson, Encyclopaedia of Typefaces, $4^{\text {th }}$ edn., Cassell \& Co., London, 1970; Caslon, Catalogue of Typefaces, Caslon and Co., London, n.d.; Fan Street Foundry, Selections from the Specimen Book of the Fann Street Foundry, Reed and Fox, London, 1873; A. and I. Tubaro, Lettering, Thames and Husdon, London, 1994.

${ }^{40}$ Eskilson, op. cit. p. 26.

${ }^{41}$ Miller, op. cit. presents samples of three-dimensional lettering from the $15^{\text {th }}$ century.

${ }^{42}$ See the many historical examples reproduced in R. Massin, Letter and Image, Studio Vista, London, 1970.

43 Jaspert \& Johnson, op. cit., p. 199.

${ }^{44}$ Miller, op. cit., p. 3.

${ }^{45}$ Ibid. 
${ }^{46}$ Ibid., p. 55.

47 T. Rosenberger \& R. L. MacNiel, 'Prosodic Font: Translating Speech into Graphics,' CHI '99 extended abstracts on human factors in computing systems, 1999, pp. 252 - 253, < http://alumni.media.mit.edu/ tara/CHI1999.pdf > accessed 13 July 132011.

; Miller, op. cit., p. 5-6.

${ }^{48}$ P.Greenhalgh, Modernism in Design, Reaktion Books, London, 1990, p. 10.

${ }^{49}$ P. Jobling \& D. Crowley, Graphic Design: Reproduction and Representation Since 1800, Manchester University Press, Manchester, 1996, p. 141; M. Mills, 'Herbert Bayer's Universal Type in its Historical Contexts', in The ABCs of the Bauhaus and Design Theory, eds. E. Lupton \& J. Abbott Miller, Thames \& Hudson, London, 1993, p. 41.

${ }^{50}$ Ibid. Arguably, any letterform can be seen as constructed from smaller components: letterforms have always been configurations, constructed from a series of separate strokes. However, in modernist typographic practice, letters are formed from geometric components that remain physically separate from their neighbours. While strokes in most letterforms tend to connect, in 'modular construction' the forms may appear separate even in the final letter, with gaps between component parts.

${ }^{51}$ Greenhalgh, op. cit., p. 14.

52 This process of reconstructing the letter from its essential elements differed from the experiments conducted by the Académie des Sciences (see 2.2.1) not least because its aims were to create an artificial - rather than natural - purity and universality.

${ }^{53}$ Miller, op. cit., p. 6.

${ }^{54}$ D. Ryan, Letter Perfect: The Art of Modernist Typography 1896-1953, Pomegranate, California, 2001, pp. 40, 58.

${ }_{55}^{55}$ Tubaro \& Tubaro, op. cit., p. 33.

${ }^{56}$ Greenhalgh, op. cit., p. 10.

${ }^{57}$ Ryan, op. cit., p. 7.

58 Ibid., p. 58.

${ }^{59}$ J. Abbott Miller \& E. Lupton, 'A Natural History of Typography', in Looking Closer: Critical Writings on Design, ed. M. Bierut, Allworth Press, New York, 1994, p. 23.

${ }^{60}$ Massin, op. cit., p. 260.

${ }^{61}$ H. Spencer \& R. Poynor, Pioneers of Modern Typography, MIT Press, Mass, 2004, p. 27.

62 Ibid.

${ }^{63}$ Since identities are not mutually exclusive. When forms are substituted for one another, as in modular construction, new identities can be introduced with or without replacing an old identity.

${ }^{64}$ Ibid., p. 87.

65 Ibid., p. 264

${ }^{66}$ MPC, 'Channel 4 idents', n.d., < http://www.moving-

picture.com/index.php?option=com content\&view=article\&id=341\&Itemid=873\&contentview=single\&section=1\&pa genum=1> accessed 19 July 2011.

${ }^{67}$ Hillner, 'op. cit. 